\title{
GAMBARAN PEMBERIAN OBAT PADA PENDERITA HIPERTENSI DI PUSKESMAS RAWANG
}

\author{
Tuty Taslim ${ }^{1}$, Yani Anggela Betris ${ }^{2}$ \\ ${ }^{1,2}$ Akademi Farmasi Prayoga \\ Email korespondensi : tutytaslim@gmail.com
}

\begin{abstract}
ABSTRAK
Hipertensi merupakan penyakit yang banyak menyebabkan kematian, karena banyak yang tidak menyadarinya.Orang dikatakan mengalami hipertensi jika memiliki tekanan darah di atas 140/90 mmHg setelah dilakukan pengecekan secara berkala. Di Puskesmas Rawang hipertensi merupakan penyakit kedua tertinggi dari 10 penyakit terbanyak yang ada di sana. Tujuan penelitian ini adalah untuk mendapatkan gambaran pemberian obat pada penderita hipertensi pada bulan April sampai bulan Juni 2019 dengan menggunakan metode penelitian observasional dengan pengambilan data retrospektif dari resep pasien yang memenuhi kriteria inklusi. Hasil penelitian menunjukkan perempuan lebih banyak menderita hipertensi yaitu $82 \%$. Sedangkan dari kriteria usia pasien yang paling banyak menderita hipertensi yaitu pada usia 41 - 60 tahun sebesar 53,8\%. Untuk pemberian obat di Puskesmas Rawang Padang terbanyak diberikan yaitu obat amlodipin dengan persentase sebesar $89 \%$.
\end{abstract}

Kata kunci : Hipertensi, Retrospektif, Puskesmas Rawang 


\title{
OVERVIEW OF DRUGS IN PATIENTS WITH HYPERTENSION AT PUSKESMAS RAWANG
}

\begin{abstract}
Hypertension is a disease that often causes death because many people do not realize it. People have hypertension if the blood pressure above 140/90 $\mathrm{mmHg}$ after regular checking. In Puskesmas Rawang, hypertension is the second-highest disease. This study aims to overview drug administration in patients hypertension. This research is an observational descriptive study using retrospective data with the inclusion criteria. Data was taken from the recipes in April till June 2019 period. Based on the research, $82 \%$ women more suffer than men. While the age criteria from $41-61$ years was 53.8\%. The majority of drugs were given in Puskesmas Rawang was amlodipine with a percentage of $89 \%$.
\end{abstract}

Keywords : Hypertension, Retrospective, Puskesmas Rawang

\section{PENDAHULUAN}

Hipertensi merupakan salah satu penyakit yang paling umum dan paling banyak ditemui pada saat ini. Hal itu terjadi karena beberapa faktor penyebab salah satunya yaitu pola hidup yang tidak sehat, seperti sering memakan makanan siap saji yang tinggi kadar natriumnya, sering begadang, dan malas untuk olahraga. Faktor lain yang memberikan peluang besar seseorang mendirita hipertensi adalah faktor keturunan.

Penyakit ini merupakan salah satu penyebab utama kematian. Sekitar $20 \%$ dari orang dewasa di negara maju dan sekitar $65 \%$ dari semua orang yang berumur lebih dari 65 tahun memiliki tekanan darah tinggi. Hipertensi merupakan penyakit nomor tiga yang menyebabkan kematian di Indonesia, yaitu mencapai $31,7 \%$ dari populasi pada usia 18 tahun ke atas (Rumagit, dkk., 2012). Penderita hipertensi di
Indonesia diperkirakan 15 juta orang tetapi hanya $4 \%$ yang merupakan hipertensi terkontrol. Prevalensi 6-15\% pada orang dewasa, $50 \%$ diantaranya tidak menyadari sebagai penderita hipertensi sehingga mereka cenderung untuk menjadi hipertensi berat karena tidak mengetahui faktor resikonya, dan 90\% merupakan hipertensi esensial (Mutmainah dkk., 2010).

Negara maju seperti Amerika paling sedikit $30 \%$ pasien hipertensi tidak menyadari kondisi mereka dan hanya $31 \%$ pasien yang diobati mencapai target tekanan darah yang diinginkan dibawah 140/90 mmHg. Di Indonesia dengan tingkat kesadaran akan kesehatan yang lebih rendah, jumlah pasien yang tidak menyadari bahwa dirinya menderita hipertensi dan yang tidak mematuhi minum obat kemungkinan lebih besar (Rumagit, dkk., 2012). Karena banyaknya masyarakat yang masih rendah tingkat 
kesadarannya akan kesehatan yang menyebabkan angka kematian di Indonesia oleh penyakit hipertensi ini semakin tinggi. Padahal sekarang ini masyarakat sudah difasilitasi untuk berobat dengan gratis, salah satunya yaitu menggunakan kartu BPJS.

Kesehatan masyarakat secara umum telah diberikan fasilitas pengobatan melalui pelayanan BPJS. Menurut Permenkes RI No. 75 Tahun 2014 Puskesmas merupakan fasilitas pelayanan kesehatan yang menyelenggarakan upaya kesehatan masyarakat dan upaya kesehatan perseorangan tingkat pertama, dengan lebih mengutamakan upaya promotif dan preventif, untuk mencapai derajat kesehatan masyarakat yang setinggitingginya. Salah satunya yaitu Puskesmas Rawang Padang yang berlokasi di komplek perumahan Jundul Rawang Kecamatan Padang Selatan. Puskesmas Rawang termasuk Puskesmas yang ramai dikunjungi pasien, dari pasien yang berusia bayi, balita, remaja, dewasa, hingga usia lanjut. Penyakit terbanyak yang ditangani di Puskesmas Rawang pada tahun 2018 salah satunya yaitu penyakit hipertensi atau biasa disebut tekanan darah tinggi yang menempati urutan ke 2 dari 10 penyakit terbanyak. Menurut Pedoman Pegobatan Dasar di Puskesmas untuk penyakit hipertensi obat-obat yang digunakan adalah Hidroklorotiazid, Reserpin, Propanolol, Kaptopril, dan Nifedipin (Depkes, 2007), sedangkan obat yang memang tersedia di Puskesmas Rawang berdasarkan stok obat yang memang disediakan dalam program pemerintah melalui jalur distribusi dari Dinas Kesehatan Kota Padang adalah Captopril, Furosemide, Hidroklorotiazid dan Amlodipin. Untuk itu dilakukan penelitian bertujuan mengetahui gambaran pemberian obat hipertensi di Puskesmas Rawang Padang sehingga dapat digunakan sebagai bahan masukan dan evaluasi sehingga dapat meningkatkan kualitas kesehatan masyarakat.

\section{METODE PENELITIAN}

Penelitian ini merupakan metoda deskriptif non eksperimental dengan pengambilan data secara retrospektif dari resep-resep perioda bulan AprilJuni 2019 yang ada di Puskesmas Rawang. Kriteria inklusi yang ditentukan adalah resep-resep yang memuat obat-obat hipertensi yang ada selama perioda pengamatan, dan resepresep tersebut dikelompokkan berdasarkan jenis kelamin, usia dan jenis obat, sedangkan kriteria eksklusi adalah resep-resep yang tidak memuat obat-obat hipertensi. Setelah pengelompokkan data dikerjakan, akan dilakukan analisis data secara deskriptif dan disimpulkan.

\section{HASIL DAN PEMBAHASAN}

Hasil penelitian menunjukkan untuk kriteria jenis kelamin perempuan memiliki persentase lebih besar dari laki-laki yaitu sebesar $82 \%$ sedangkan untuk laki-laki sebesar $18 \%$. 
Tabel 1. Jumlah pasien berdasarkan jenis kelamin

\begin{tabular}{ccc}
\hline Jenis kelamin & Jumlah (orang) & Persentasae (\%) \\
\hline Laki-laki & 69 & 18 \\
Perempuan & 314 & 82 \\
Total & 383 & 100
\end{tabular}

Wanita mempunyai resiko yang lebih besar untuk mengalami hipertensi dibandingkan dengan laki-laki terutama pada perempuan yang telah menopause, karena terjadi penurunan hormon esterogen dan progesteron yang memberikan perlindungan pada perempuan dari risiko penebalan dinding pembuluh darah atau aterosklerosis. Ini sesuai dengan penelitian Bustan (2007) yang juga menemukan hal yang sama. Pengamatan ini diperkuat pada saat dilakukan pengelompokkan usia berdasarkan Departemen Kesehatan tahun 2009.

Tabel 2. Jumlah pasien berdasarkan usia

\begin{tabular}{ccccc}
\hline \multirow{2}{*}{$\begin{array}{c}\text { Kelompok usia } \\
\text { (tahun) }\end{array}$} & \multicolumn{2}{c}{ Jenis kelamin } & \multicolumn{2}{c}{ Persentase (\%) } \\
\cline { 2 - 5 } & Laki-laki & Perempuan & Laki-laki & Perempuan \\
\hline $26-35$ & 5 & 5 & 1,3 & 1,3 \\
$36-45$ & 5 & 36 & 1,3 & 9,4 \\
$46-55$ & 11 & 94 & 2,9 & 24,5 \\
$56-65$ & 25 & 95 & 6,5 & 24,8 \\
$>65$ & 24 & 83 & 6,3 & 21,7 \\
\hline Total & 70 & 313 & 18,3 & 81,7 \\
\hline
\end{tabular}

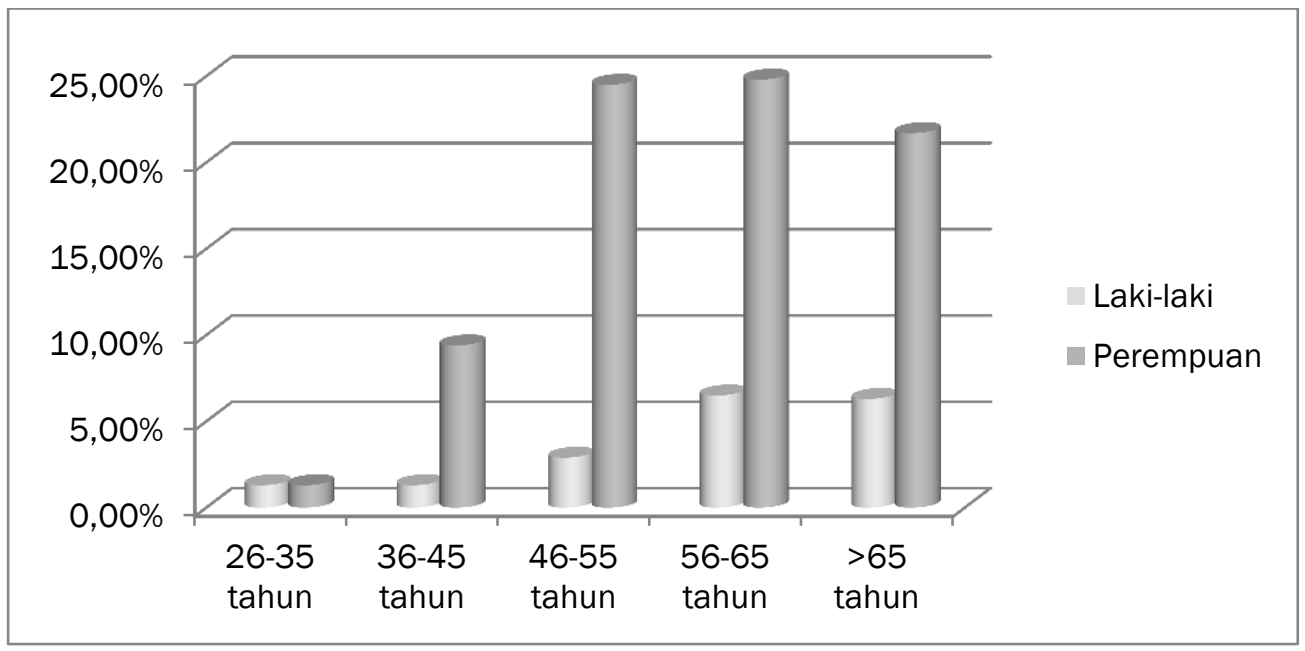

Gambar 1. Diagram persentase kriteria usia 
Pada usia menginjak 36 tahun merupakan usia produktif manusia dimana manusia bekerja untuk menghasilkan sesuatu memenuhi kebutuhan hidup dalam keluarga masing-masing. Bukan hal yang aneh pada jaman sekarang dalam sebuah keluarga, perempuan disamping menjadi seorang istri jugamenjadi orang yang akan membantu meningkatkan pendapatan keluarga agar dapat hidup sesuai dengan kondisi yang diinginkan. Peranan seorang perempuan tetap saja melekat sebagai seorang ibu yang akan mengurusi, membereskan pekerjaan dan membahagiakan keluarganya disamping juga membagi diri dalam pekerjaan di luar rumah. Saat seorang perempuan memasuki usia menopause yang biasanya terjadi antara usia 45-55 tahun, maka perubahan hormonal, keadaan stres, kelelahan, dan pola konsumsi makan yang tidak terkontrol juga berperan sangat besar dalam kejadian hipertensi. Berdasarkan hasil Riset Kesehatan Dasar (2013) prevalensi hipertensi pada perempuan dibanding laki-laki juga menunjukkan hal yang sama. Dan peningkatan umur akan menyebabkan beberapa perubahan fisiologis, pada usia lanjut terjadi peningkatan resistensi perifer dan aktifitas simpatik, pengaturan tekanan darah yaitu refleks baroreseptor pada usia lanjut sensitivitasnya sudah berkurang, sedangkan peran ginjal juga sudah berkurang dimana aliran darah ginjal dan laju filtrasi glomerulus menurun (Saputra, 2013). Tetapi ada juga penelitian dari Prasetyaningrum (2014) menyatakan laki-laki lebih berisiko mengalami hipertensi dibandingkan perempuan saat usia $<45$ tahun, tetapi saat usia $>65$ tahun perempuan lebih berisiko mengalami hipertensi dibanding laki-laki setelah wanita memasuki masa menopause, dikarenakan faktor hormonal.

Berdasarkan Formularium Nasional 2019, obat-obat hipertensi yang disetujui untuk diberikan pada fasilitas kesehatan tingkat 1 antara lain adalah Amlodipin, Atenolol, Hidroklortiazid, Captopril, Klortalidon, Lisinopril, Furosemid dan Spironolakton. Jenis obat-obat hipertensi yang ada di puskesmas Rawangpada bulan Januari-Maret 2019 tersebut hanyalah Amlodipin, Captopril dan Furosemid sedangkan untuk obatobat lainnya sedang tidak ada.

Tabel 3. Jumlah pasien berdasarkan jenis obat hipertensi

\begin{tabular}{ccc}
\hline Jenis obat & $\begin{array}{c}\text { Jumlah Pasien } \\
\text { (orang) }\end{array}$ & Persentase (\%) \\
\hline Amlodipin & 341 & 89 \\
Captopril & 18 & 4,7 \\
Furosemid & 8 & 2,1 \\
Amlodipin + Captopril & 8 & 2,1 \\
Amlodipin + Furosemid & 2 & 0,5 \\
Captopril + Furosemid & 5 & 1,3 \\
Amlodipin + Captopril + Furosemid & 1 & 0,3 \\
\hline
\end{tabular}




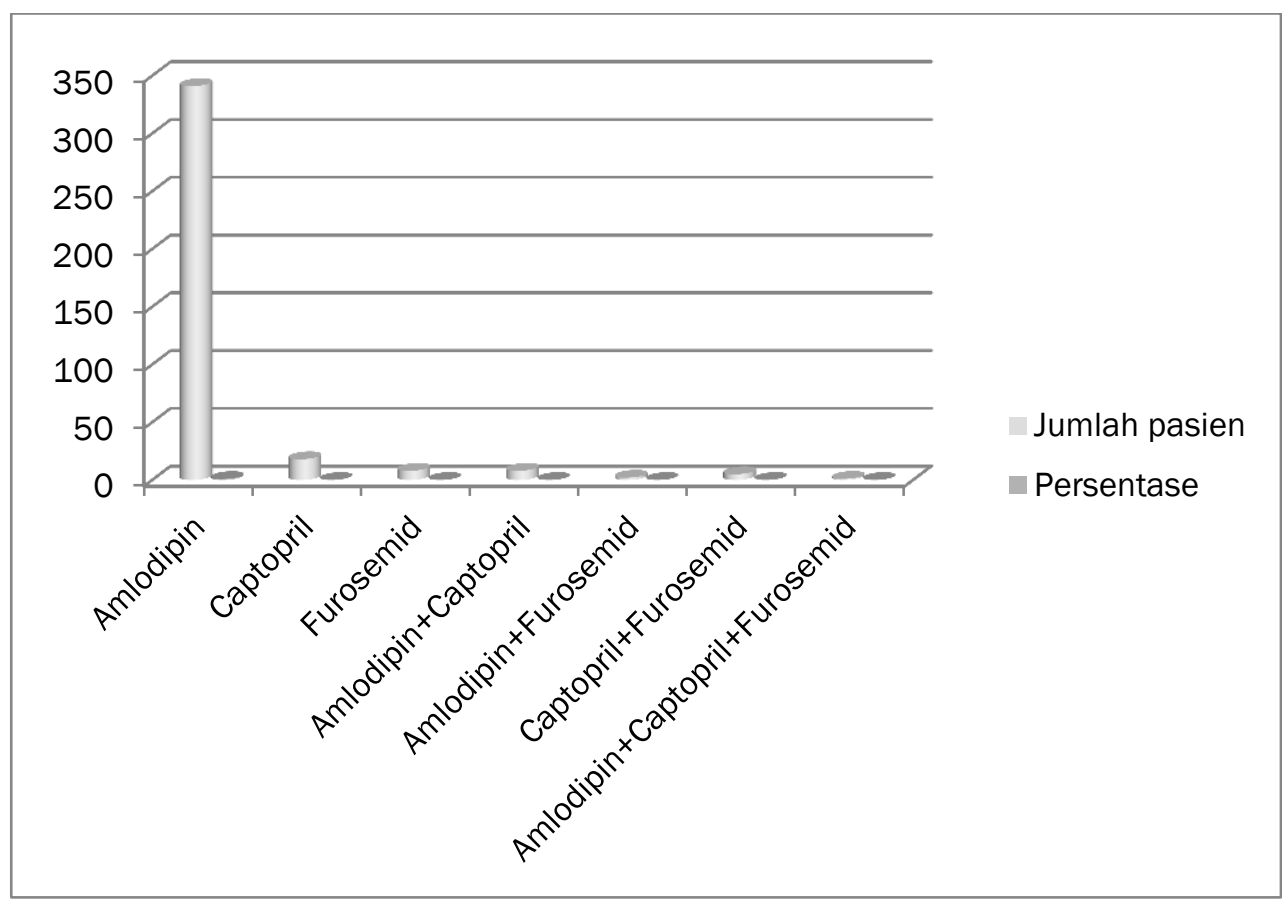

Gambar 2. Diagram persentase obat hipertensi di Puskesmas Rawang

Pemberian obat hipertensi di Puskesmas Rawang pada periode Januari-Maret 2019, obat Amlodipin merupakan obat terbanyak yaitu mencapai $89 \%$ dibandingkan obat hipertensi yang tersedia lainnya seperti Captopril, dan Furosemid. Menurut Dharma (2017) Amlodipin memiliki kelebihan dibandingkan dengan obat hipertensi lainnya karena efisien dalam pemberian yaitu cukup satu kali sehari, menurunkan tekanan darah secara perlahan dan absorbsinya sempurna dalam tubuh, terutama bagi penderita berusia lanjut. Untuk Captopril dan Furosemid hanya beberapa yang diberikan karena persediaan obat Captopril dan Furosemid juga tidak banyak. Selain itu obat Captopril juga memiliki efek samping menyebabkan batuk kering. Pemberian obat tersebut juga telah dipertimbangkan dengan kebutuhan pasien tersebut disamping ketersediaan obat yang ada. Hasil penelitian Baharuddin (2013) menunjukkan bahwa perbandingan efektifitas menurunkan tekanan darah sistol dan diastol oleh Amlodipin lebih tinggi dari Captopril, sedangkan antara Hidroklortiazid dengan Captopril dan antara Hidroklortiazid dengan Amlodipin tidak ada perbedaan bermakna. Adapun terhadap 16 pasien lainnya yang rata-rata berusia $>60$ tahun diberikan obat hipertensi dengan kombinasi dengan obat hipertensi lainnya. Seperti pada penelitian ini ditemukan kombinasi obat yaitu Amlodipin dengan Captopril; Amlodipin dengan Furosemid; Captopril dengan Furosemid dan Amlodipin dengan Captopril dan Furosemid. Diberikannya kombinasi obat pada penderita hipertensi agar tercapainya target tekanan darah yang diinginkan disamping menghindari 
komplikasi lainnya pada penderita hipertensi.

\section{SIMPULAN}

Kesimpulan dari penelitian ini adalah :

1. Pemberian obat hipertensi banyak ditemukan pada pasien berjenis kelamin perempuan dibandingkan dengan laki-laki

2. Perlu dilakukan peningkatan pemahaman tentang penyakit hipertensi terutama pada perempuan, sehingga dapat lebih meningkatkan kualitas hidup dan mencegah penyakit hipertensi.

3. Minimnya jenis obat hipertensi yang tersedia di puskesmas sehingga tidak banyak pilihan yang dapat diresepkan.

4. Pilihan terbanyak yaitu obat Amlodipin karena lebih efisien dalam pemberian dan juga dari ketersediaan obat dan kebutuhan pasien.

\section{UCAPAN TERIMAKASIH}

Pada kesempatan ini, peneliti ingin menyampaikan ucapan terima kasih kepada Pimpinan Puskesmas Rawang yang telah memberikan kesempatan untuk mengumpulkan data yang dibutuhkan.

\section{DAFTAR PUSTAKA}

Bagian Farmakologi, 2004, Farmakologi Dan Terapi edisi 4, Jakarta : Balai Penerbit FKUI.

Baharuddin, dkk. 2013, Perbandingan Efektifitas Dan Efek Samping Obat Antihipertensi Terhadap Penurunan
Tekanan Darah Pasien Hipertensi, Jurnal Universitas Hasanuddin.

Bustan, MN., 2007, Epidemiologi Penyakit Tidak Menular, Cetakan 2 Rineka Cipta, Jakarta.

Corwin, Elizabeth J., 2000, Buku Saku Patofisiologi, Jakarta : EGC.

Departemen Keshatan, 2007, Pedoman Pengobatan Dasar Di Puskesmas 2007, Jakarta : Depkes RI.

Departemen Farmakologi, 2008, Kumpulan Kuliah Farmakologi edisi 2, Jakarta : EGC.

Goodman dan Gilman, 2010, Manual Farmakologi Dan Terapi edisi 5, Jakarta : EGC.

Katzung, Bertram G, 2001, Farmakologi Dasar Dan Klinis edisi 1, Jakarta : Salemba Medika.

Katzung, Bertram G, 2010, Farmakologi Dasar Dan Klinik edisi 10, Jakarta : EGC.

Kee, JL., dan Evelyn, RH., 1996, Farmakologi Pendekatan Proses Keperawatan, Jakarta : EGC.

Kemenkes RI, 2013, Riset Kesehatan Dasar (Riskesdas), Jakarta : Kementrian Republik Indonesia.

Mahmuda, S., dkk, 2015, Hubungan Gaya Hidup Dan Pola Makan Dengan Kejadian Hipertensi Pada Lansia Di Kelurahan Sawanagan Baru Kota 
Depok Tahun 2015, Biomedika. Vol 7 (2), hal 43-51.

Michael, JN., 2006, At a Glance Farmakologi Medis Edisi 5, Jakarta : Erlangga.

Mutmainah, $\mathrm{N}$ dan Rahmawati, $\mathrm{M}$. 2010, Hubungan Antara Kepatuhan Penggunaan Obat Dan Keberhasilan Terapi Pada Pasien Hipertensi Di Rumah Sakit Daerah Surakarta Tahun 2010, Pharmacon, Vol 11 No 2 hal 5156.

Mutschler, E, 1991, Dinamika Obat Edisi 5, Bandung : ITB.

Permenkes RI No. 75 Tahun 2014 Tentang Puskesmas.

Prasetyaningrum, YI., 2014, Hipertensi Bukan Untuk Ditakuti, Jakarta : FMedia.

Rumagit, BI., Pojoh, JA., Manampiring, VN., 2012, Studi Deskriptif Pemberian
Obat Pada Pasien Hipertensi Di Puskesmas Sario, Jurnal Ilmiah Farmasi, Vol 3 (2), hal 64-69.

Saputra, B., dkk. 2013, Profil Penderita Hipertensi Di RSUD Jombang Periode Januari-Desember 2011, Jurnal Vol 9 No 2, hal. 116-120.

Sudarsono, E., dkk, 2017, Peningkatan Pengetahuan Tentang Hipertensi Guna Perbaikan Tekanan Darah Pada Anak Muda Di Dusun Japanan, Margodadi, Sayegan, Sleman, Yoghyakarta, Jurnal Pengabdian Kepada Masyarakat, Vol. 3 No 1, hal. 26-38.

Tara, E. dan Soetrisno, E., 1993, Buku Pintar Terapi Hipertensi, Jakarta : Restu Agung dan Taramedia.

Tjay, T.H dan Rahardja, K., 2007, Obat-Obat Penting Edisi 6, Jakarta : Gramedia. 